\title{
Reoperations within 48 hours following 7942 pediatric neurosurgery procedures
}

\author{
Anil K. Roy, MD, ${ }^{2}$ Jason Chu, MD, MSc, ${ }^{2}$ Caroline Bozeman, BS, ${ }^{1}$ Samir Sarda, MPH, ${ }^{3}$ \\ Michael Sawvel, DO, ${ }^{1}$ and Joshua J. Chern, MD, PhD ${ }^{1,2}$
}

${ }^{1}$ Pediatric Neurosurgery Associates, Children's Healthcare of Atlanta; ${ }^{2}$ Department of Neurosurgery, Emory University School of Medicine; and ${ }^{3}$ Department of Health Policy \& Management, Rollins School of Public Health, Emory University, Atlanta, Georgia

\begin{abstract}
OBJECTIVE Various indicators are used to evaluate the quality of care delivered by surgical services, one of which is early reoperation rate. The indications and rate of reoperations within a 48-hour time period have not been previously reported for pediatric neurosurgery.
\end{abstract}

METHODS Between May 1, 2009, and December 30, 2014, 7942 surgeries were performed by the pediatric neurosurgery service in the operating rooms at a single institution. Demographic, socioeconomic, and clinical characteristics associated with each of the operations were prospectively collected. The procedures were grouped into 31 categories based on the nature of the procedure and underlying diseases. Reoperations within 48 hours at the conclusion of the index surgery were reviewed to determine whether the reoperation was planned or unplanned. Multivariate logistic regression was employed to analyze risk factors associated with unplanned reoperations.

RESULTS Cerebrospinal fluid shunt- and hydrocephalus-related surgeries accounted for 3245 (40.8\%) of the 7942 procedures. Spinal procedures, craniotomy for tumor resections, craniotomy for traumatic injury, and craniofacial reconstructions accounted for an additional $8.7 \%, 6.8 \%, 4.5 \%$, and $4.5 \%$ of surgical volume. There were 221 reoperations within 48 hours of the index surgery, yielding an overall incidence of $2.78 \% ; 159$ of the reoperation were unplanned. Of these 159 unplanned reoperations, 121 followed index operations involving shunt manipulations. Using unplanned reoperations as the dependent variable $(n=159)$, index operations with a starting time after 3 PM and admission through the emergency department (ED) were associated with a two- to threefold increase in the likelihood of reoperations (afterhour surgery, odds ratio [OR] 2.01 [95\% Cl 1.43-2.83, p< 0.001]; ED admission, OR 1.97 (95\% Cl 1.32-2.96, $p<0.05]$ ).

CONCLUSIONS Approximately $25 \%$ of the reoperations within 48 hours of a pediatric neurosurgical procedure were planned. When reoperations were unplanned, contributing factors could be both surgeon related and system related. Further study is required to determine the extent to which these reoperations are preventable. The utility of unplanned reoperation as a quality indicator is dependent on proper definition, analysis, and calculation.

https://thejns.org/doi/abs/10.3171/2016.11.PEDS16411

KEY WORDS reoperation; pediatric neurosurgery; quality assurance

$\mathrm{T}$ HIRTY-DAY readmission and reoperation rates have been used as quality indicators across surgical specialties., ${ }^{1,4-6,8-12,14}$ This relatively long time interval (30 days) enables one to capture complications resulting from complex interplays among preoperative, intraoperative, and postoperative factors following the index surgery. For example, surgical infection could be a direct result of breaches of proper sterile technique, but it could also result from poor wound care or lack of access to medical care.
Determining the relative contributions of different factors to the eventual complication occurrence is often difficult, and it likely would vary from patient to patient.

The study of early reoperations (within 3 or fewer days) has received little attention in the neurosurgical or surgical literature. ${ }^{3,7}$ We believe an analysis of early reoperations would minimize the contributions of postoperative factors to the cause of complications. Since little time has passed, early reoperation is likely to be the direct consequence of

ABBREVIATIONS ACGME = Accreditation Council for Graduate Medical Education; ED = emergency department; EVD = external ventricular drain; ICP = intracranial pressure; ICU = intensive care unit; LP = lumboperitoneal; $\mathrm{NICU}=$ neonatal ICU; SP/CP = subdural-peritoneal/cyst peritoneal; VA = ventriculoatrial; VAD = ventricular access device; $V P=$ ventriculoperitoneal.

ACCOMPANYING EDITORIAL See pp 632-633. DOI: 10.3171/2016.12.PEDS16618.

SUBMITTED July 15, 2016. ACCEPTED November 7, 2016.

INCLUDE WHEN CITING Published online March 31, 2017; DOI: 10.3171/2016.11.PEDS16411. 
adverse events that occurred intraoperatively. These events are more likely to be modifiable because they occurred in a relatively controlled environment (operating room). That being said, it should be noted that the shortened period will not eliminate the contributions of the preoperative factors to complication occurrence.

In the present study, we report the incidence of early reoperation after 7942 pediatric neurosurgical procedures in a single institution. The characteristics of both surgeries and patients are described and analyzed for their associations with the reoperation. Lessons learned, preventability, and future directions will then be discussed.

\section{Methods}

\section{Inclusion and Exclusion Criteria}

This study included 7942 neurosurgical procedures (index surgery) that were performed in the operating rooms between May 1, 2009, and December 30, 2015, at Children's Healthcare of Atlanta. Neurosurgical procedures performed in the intensive care units (ICUs) were not included. These neurosurgical procedures were performed by board-certified and board-eligible pediatric neurosurgeons and fellows.

\section{Categorizing Neurosurgical Procedures}

All procedures, as shown in Table 1, were categorized and subcategorized based on review of operative reports and electronic medical records. The categories were adapted from the Accreditation Council for Graduate Medical Education (ACGME) Neurological Surgery-defined case categories (CPT code mapping areas) with modifications. For instance, ventricular access device placement falls under "minor procedure" in the ACGME case categories but is labeled as a stand-alone category in this study because of the frequency of this operation in the pediatric population. This categorization was used in our previous studies..$^{10}$

If a patient underwent two separate procedures in a single operation, the procedure of higher acuity, adjudicated by the senior author (J.J.C.), was designated to be the representative procedure and categorized as such. For example, if a patient underwent external ventricular drain (EVD) placement and craniotomy for tumor resection during a single visit to the operating room, the procedure is categorized as a "craniotomy for tumor resection." However, if the EVD and tumor resection were performed in two separate visits to the operating room, they were then counted as two separate procedures.

Shunt-related surgeries were categorized by involved anatomical compartments: ventriculoperitoneal (VP), ventriculoatrial (VA), lumboperitoneal (LP), subduralperitoneal/cyst peritoneal (SP/CP), syrinx-pleural, ventriculopleural, and lumbopleural. These were then further subdivided into "shunt insertion" and "shunt revision" categories. A final category was added to characterize surgeries that required shunt externalization or removal. If a shunt insertion or revision was accompanied by endoscopic fenestration of loculated ventricular cysts, it was categorized as a shunt procedure and not an endoscopic procedure.

Outside of CSF shunt procedures, three other catego-
TABLE 1. Surgical categories, numbers of procedures, and procedure duration in each category

\begin{tabular}{|c|c|c|c|}
\hline \multirow[b]{2}{*}{ Category* } & \multirow{2}{*}{$\begin{array}{c}\text { No. } \\
\text { of } \\
\text { Ops }\end{array}$} & \multicolumn{2}{|c|}{$\begin{array}{l}\text { Procedure Duration } \\
\text { (mins) }\end{array}$} \\
\hline & & Mean \pm SD & Median \\
\hline \multicolumn{4}{|l|}{ Shunt procedures } \\
\hline VP shunt insertion & 851 & $42.31 \pm 21.18$ & 36 \\
\hline VP shunt revision & 1725 & $39.20 \pm 25.40$ & 34 \\
\hline VA shunt insertion & 116 & $58.75 \pm 24.67$ & 54 \\
\hline VA shunt revision & 159 & $44.48 \pm 23.54$ & 40 \\
\hline LP shunt insertion & 60 & $55.13 \pm 25.72$ & 48 \\
\hline LP shunt revision & 14 & $46.50 \pm 17.83$ & 47 \\
\hline SP/CP shunt insertion & 54 & $40.43 \pm 12.34$ & 40 \\
\hline SP/CP shunt revision & 7 & $47.14 \pm 25.03$ & 37 \\
\hline Other shunt insertion & 21 & $74.33 \pm 43.70$ & 71 \\
\hline Other shunt revision & 9 & $119.22 \pm 81.43$ & 76 \\
\hline Shunt externalization/removal & 229 & $34.70 \pm 41.37$ & 23 \\
\hline \multicolumn{4}{|l|}{ Cranial procedures } \\
\hline Craniotomy for tumor resection & 541 & $262.16 \pm 129.21$ & 254 \\
\hline Craniotomy for trauma & 346 & $74.64 \pm 44.60$ & 67 \\
\hline Craniotomy for craniosynostosis & 359 & $151.09 \pm 54.46$ & 141 \\
\hline Chiari decompression & 311 & $130.57 \pm 52.26$ & 127 \\
\hline Craniotomy for epilepsy & 149 & $252.67 \pm 117.00$ & 216 \\
\hline Cranioplasty & 155 & $93.45 \pm 46.66$ & 81 \\
\hline Craniotomy for vascular lesions & 64 & $275.89 \pm 287.78$ & 180 \\
\hline Transsphenoidal surgery & 53 & $65.11 \pm 72.33$ & 27 \\
\hline Other craniotomies & 109 & $77.75 \pm 85.72$ & 58 \\
\hline $\begin{array}{l}\text { Endoscopic third ventriculos- } \\
\text { tomy }\end{array}$ & 141 & $62.48 \pm 30.97$ & 54 \\
\hline Stereotactic brain biopsy & 67 & $75.82 \pm 34.19$ & 68 \\
\hline VAD/EVD placement & 518 & $28.51 \pm 20.56$ & 19 \\
\hline \multicolumn{4}{|l|}{ Spinal procedures } \\
\hline Laminectomy for detethering & 558 & $148.36 \pm 101.48$ & 121 \\
\hline Spinal fusion & 134 & $224.10 \pm 146.94$ & 176 \\
\hline \multicolumn{4}{|l|}{ Other procedures } \\
\hline Wound revision or washout & 263 & $37.20 \pm 33.14$ & 28 \\
\hline VNS insertion \& revision & 230 & $63.40 \pm 33.91$ & 60 \\
\hline $\begin{array}{l}\text { Baclofen pump insertion \& } \\
\text { revision }\end{array}$ & 214 & $70.66 \pm 67.34$ & 57 \\
\hline $\begin{array}{l}\text { Brachial plexus \& peripheral } \\
\text { nerve }\end{array}$ & 15 & $128.00 \pm 104.00$ & 102 \\
\hline Myelomeningocele repair & 127 & $77.03 \pm 46.39$ & 68 \\
\hline Minor & 343 & $50.68 \pm 391.11$ & 15 \\
\hline
\end{tabular}

ries were named as "cranial," "spine," and "others," similar to that which Sarda et al.$^{10}$ have previously published. The categories are shown in Table 1. Within the cranial procedures, "other craniotomies" included decompressive craniectomy for intracranial hypertension unrelated to trauma, for CSF leak repair, for evacuation of epidural, subdural, or intracranial abscesses, for open arachnoid cyst fenestra- 
tions, for osteomyelitis, and for fibrous dysplasia, among others.

Within the spinal procedures, instrumented fusions were separated from the remaining spinal procedures. The "laminectomy" category included simple and complex tethered cord release, cervical laminectomy, and spinal cord neoplasm resection.

The last category, "others," had a "minor" section that included intracranial pressure (ICP) monitor placement, application or removal of halo orthosis, placement of lumbar drain, muscle and/or nerve biopsies, and others. This category also included cases that were cancelled or aborted intraoperatively.

\section{Other Data Fields}

Demographic, socioeconomic, and clinical characteristics were prospectively collected electronically with the following software: Epic ASAP (emergency department [ED]), OpTime (surgical department), EpicCare Inpatient (inpatient service), and ADT (admission-discharge-transfer application). Demographic data fields that were collected included age, primary language, race/ethnicity, zip code, and primary payer status (public assistance and selfpay vs private insurance). Clinical data fields included surgeon identity, length of hospital stay, procedure start and finish times, admission sources (elective same-day admissions vs admission from ED vs inpatient status at the time of surgery), airway status after surgery, CPT code and surgeon-dictated procedure comments (a short description entered by operating room circulating nurses), and operative reports. If surgery began after 3 PM but before $7 \mathrm{AM}$, it was labeled as an "after hour" surgery. This specific time point was chosen as shift change for nurses at our institution begins at $3 \mathrm{PM}$. Admissions to pediatric and neonatal ICUs (NICUs) after the surgery were also captured.

If an index procedure was followed by another neurosurgical procedure within 48 hours from the procedure stop time, the index procedure was designated as an event of interest. If the reoperation was followed by another neurosurgical procedure within 48 hours, the reoperation itself was also labeled as an event. There were 5 such incidents (having 3 neurosurgical procedures within a 5-day period) in the study period.

\section{Statistical Analysis}

Multivariate logistic regression analysis was used to assess whether risk factors independently correlated with dependent variables. The multivariate model was constructed based on the following independent variables: age (in months), self-pay or public assistance pay, Caucasian race (yes/no), English speaking (yes/no), admission from ED (yes/no), ICU (including NICU or pediatric ICU) stay after surgery (yes/no), procedure start time after 3 PM (yes/no), posting status (emergency surgery vs others), admission source (elective outpatient admission vs others), intubation status after the surgery, and surgeon identity. Collinearity among variables was detected if the tolerance value was less than 0.2. Univariate associations of surgery types with various dependent variables were analyzed, and those surgery types that were found to be
TABLE 2. Patient characteristics and other variables associated with 7942 index surgeries

\begin{tabular}{lc}
\hline \multicolumn{1}{c}{ Variable } & Value $(\%)^{*}$ \\
\hline Mean age (mos) & 88.7 \\
\hline Age <1 yr & $2000(25.2)$ \\
\hline Mean hospital LOS (days) & 12.2 \\
\hline LOS <3 days & $4050(51.0)$ \\
\hline English as primary language & $7263(91.5)$ \\
\hline Caucasian & $4489(56.5)$ \\
\hline Medicaid/Medicare as the primary payer & $4274(53.8)$ \\
\hline Admission from ED & $3084(38.8)$ \\
\hline Elective admission on day of surgery & $4577(57.6)$ \\
\hline Urgent \& emergent surgery & $589(7.41)$ \\
\hline Surgery starting after 3 PM & $1363(17.2)$ \\
\hline Remained intubated after surgery & $1370(17.3)$ \\
\hline ICU admissions & $2909(36.6)$ \\
\hline NICU admissions & $806(10.1)$ \\
\hline Multiple surgeries during same admission & $755(9.51)$ \\
\hline Surgeon No. & \\
\hline 1 & $1998(25.2)$ \\
\hline 2 & $1605(20.2)$ \\
\hline 3 & $1503(18.9)$ \\
\hline 4 & $1680(21.2)$ \\
\hline 5 & $719(9.1)$ \\
\hline 6 Others & $148(2.0)$ \\
\hline Values are number of patients (\%) unless otherwise indicated. \\
\hline
\end{tabular}

significant $(\mathrm{p}<0.05)$ were entered into the multivariate analysis.

\section{Results}

\section{Patient and Surgery Characteristics}

Descriptive statistics of the patient cohort and surgeries are provided in Tables 1 and 2, respectively. Approximately $25 \%$ of patients were under 1 year of age. A substantial number of patients were admitted through the ED (38.8\%); 7.4\% of the procedures were posted as emergent or urgent, and $17.2 \%$ started after 3 PM; $36.6 \%$ of the patients were discharged from the operating room to the ICU. These descriptions reflect the overall high-acuity nature of neurosurgical patients, as well as the fact that the need for neurosurgical interventions can be unpredictable.

The most commonly performed procedures were shunt related. Shunt-related procedures accounted for 3245 (40.9\%) of the 7942 events. In the study period, 1102 new shunts were implanted. As expected, there were more VP shunts than VA shunts being inserted and revised.

The most common craniotomies were for tumor resections $(n=541)$, traumatic injury $(n=346)$, craniosynostosis repair $(\mathrm{n}=359)$, and Chiari decompression $(\mathrm{n}=$ 311). Together, they represented 1557 of 2813 cranial cases (55.4\%). Craniotomy for epilepsy and cranioplasty procedures, which included patients with congenital skull defect 
and patients who underwent decompressive craniectomy, were the next two most commonly performed major cranial procedures (Table 1).

Among the "spinal procedures," treatment for occult spinal dysraphism, including filum lipoma, dermal sinus tract, dermoid tumor, diastematomyelia, and lipomyelomeningocele, was the most common $(n=558)$. There were 134 spinal fusions, including occipitocervical fusions. Last, in the "others" category, it was notable that the number of cases of wound revision and washout was significant ( $n=263,7.2 \%$ of all cases). Under the "minor" category, there were 143 cases of ICP monitor placement, 40 cases of halo vest placement, 20 cases of halo vest removal, 35 cases of lumbar drain placement, 27 cases of lumbar puncture, and 13 aborted cases, among other procedures.

\section{Reoperations Within 48 Hours of Index Surgery}

The rate of early reoperations for each category is reported in Table 3. There were 221 reoperations (2.78\%) within 48 hours of the conclusion of the index surgery. Three physicians (senior neurosurgical resident, pediatric neurosurgery fellow, and a board-certified pediatric attending) adjudicated on whether the reoperation was "planned" or "unplanned" (J.C., M.S., and J.J.C., respectively). There were complete agreements in 213 cases; for the remaining 8 cases, the final decision was based on the majority opinion. There were 62 planned reoperations and 159 unplanned reoperations.

Among the 62 planned reoperations, the most common scenarios were EVD placement followed by tumor resection $(n=16)$, and EVD or ICP monitor placement to discern shunt function followed by shunt revision $(\mathrm{n}=$ 13). Other scenarios included shunt placement after myelomeningocele closure $(n=8)$ and halo vest placement to facilitate traction prior to occipitocervical fusion $(n=4)$. There were 6 cases in which the ventriculoatrial shunt was externalized, then later internalized (reoperation), because general surgeons were not available at the time of the index procedure for vascular access.

Among the 159 index surgeries that were followed by unplanned reoperations, 117 were shunt related (Table 3). Therefore, unplanned reoperation rate for shunt-related surgeries was $3.6 \%$ (117/3245). The indications for these reoperations were as follows: intraventricular or subdural hematoma formation $(n=6)$, positive CSF culture $(n=5)$, less than optimal proximal or distal catheter location (n $=16)$, and poor wound closure $(\mathrm{n}=3)$. In 10 cases, after shunt revision or insertion, loculation of the ventricular space was discovered and a second catheter was placed or an endoscopic fenestration procedure was performed. In the remaining cases $(n=77)$, neurological symptoms persisted after shunt revision, and imaging failed to identify obvious causes. The resulting unplanned reoperations were ICP monitor placement, shunt externalization, or shunt explorations.

Indications for unplanned reoperations after cranial procedures included incomplete resection of tumor, bleeding from tumor bed, subdural or epidural bleed away from surgical sites, and decompressive craniectomy to treat brain swelling. There were 6 cases of decompressive craniectomy or intraparenchymal hematoma evacuation after
TABLE 3. Frequency of unplanned reoperations within 48 hours of index surgery, stratified by surgical category

\begin{tabular}{|c|c|}
\hline Category & No. of Unplanned Reops (\%) \\
\hline \multicolumn{2}{|l|}{ Shunt procedures } \\
\hline VP shunt insertion & $11(1.3)$ \\
\hline VP shunt revision & $84(4.9)$ \\
\hline VA shunt insertion & $6(5.2)$ \\
\hline VA shunt revision & $7(4.4)$ \\
\hline LP shunt insertion & 0 \\
\hline LP shunt revision & 0 \\
\hline SP/CP shunt insertion & 0 \\
\hline SP/CP shunt revision & 0 \\
\hline Other shunt insertion & $1(4.8)$ \\
\hline Other shunt revision & 0 \\
\hline Shunt externalization/removal & $8(3.5)$ \\
\hline \multicolumn{2}{|l|}{ Cranial procedures } \\
\hline Craniotomy for tumor resection & $5(0.9)$ \\
\hline Craniotomy for trauma & $6(1.7)$ \\
\hline Craniotomy for craniosynostosis & 0 \\
\hline Chiari decompression & 0 \\
\hline Craniotomy for epilepsy & $1(0.7)$ \\
\hline Cranioplasty & 0 \\
\hline Craniotomy for vascular lesions & 0 \\
\hline Transsphenoidal surgery & 0 \\
\hline Other craniotomies & 0 \\
\hline Endoscopic third ventriculostomy & $2(1.4)$ \\
\hline Stereotactic brain biopsy & $1(1.5)$ \\
\hline VAD/EVD placement & $7(3.3)$ \\
\hline \multicolumn{2}{|l|}{ Spinal procedures } \\
\hline Laminectomy for detethering & 0 \\
\hline Spinal fusion & 0 \\
\hline \multicolumn{2}{|l|}{ Other procedures } \\
\hline Wound revision or washout & $5(1.9)$ \\
\hline VNS insertion \& revision & 0 \\
\hline Baclofen pump insertion \& revision & 0 \\
\hline Brachial plexus \& peripheral nerve & 0 \\
\hline Myelomeningocele repair & 0 \\
\hline Minor & $5(1.5)$ \\
\hline
\end{tabular}

initial intracranial hematoma evacuation. Ventricular access devices (VADs) and EVDs were replaced because of clotting or accidental removal of the device, respectively. In 2 cases, acute failure after endoscopic third ventriculostomy required immediate reoperations. Last, there were 3 cases in which the index surgery was aborted due to anesthesia-related concerns, and the patients were taken back to the operation room within 48 hours.

\section{Risk Factors Associated With Reoperations}

Univariate and multivariate analyses were used to identify clinical and demographic factors that were predictive of unplanned reoperations $(n=159)$. The results of the univariate and multivariate analyses are summarized in 
TABLE 4. Univariate analysis of clinical and demographic factors associated with unplanned reoperations within 48 hours of index surgery

\begin{tabular}{|c|c|c|}
\hline \multirow[b]{2}{*}{ Independent Variable } & \multicolumn{2}{|c|}{$\begin{array}{l}\text { Dependent Variable: Unplanned } \\
\text { Reops w/in } 48 \text { Hrs }(n=159)\end{array}$} \\
\hline & OR $(95 \% \mathrm{Cl})$ & $p$ Value \\
\hline Age $<1 \mathrm{yr}$ & $0.66(0.44-0.99)$ & 0.043 \\
\hline Hospital LOS (days) & $1.00(1.00-1.01)$ & 0.067 \\
\hline Non-English speaking & $0.96(0.53-1.69)$ & 0.865 \\
\hline Caucasian & $1.05(0.77-1.44)$ & 0.762 \\
\hline $\begin{array}{l}\text { Medicaid/Medicare as the } \\
\text { primary payer }\end{array}$ & $1.01(0.74-1.39)$ & 0.944 \\
\hline After-hr surgery* & $3.46(2.50-4.77)$ & $<0.001$ \\
\hline $\begin{array}{l}\text { Remained intubated after } \\
\text { surgery }\end{array}$ & $1.36(0.93-1.99)$ & 0.110 \\
\hline Urgent surgery & $2.63(1.72-4.01)$ & $<0.001$ \\
\hline Admission from ED & $4.38(3.08-6.23)$ & $<0.001$ \\
\hline ICU admission after surgery & $1.27(0.92-1.74)$ & 0.146 \\
\hline NICU admission after surgery & $0.28(0.12-0.69)$ & 0.006 \\
\hline \multicolumn{3}{|l|}{ Index surgery category } \\
\hline Shunt & $4.75(3.29-6.86)$ & $<0.001$ \\
\hline Cranial & $0.42(0.28-0.62)$ & $<0.001$ \\
\hline Spinal† & - & - \\
\hline Other & $0.30(0.14-0.60)$ & 0.001 \\
\hline
\end{tabular}

Boldface type indicates statistical significance.

* After-hour surgery was defined as procedure start time after 3 PM and before 7 AM.

$\dagger$ There were no reoperations after spinal procedures.

Table 4 and Table 5, respectively. In the univariate analysis, NICU admission after surgery was identified as a protective factor against early reoperations. In this group of patients, the most common procedures were VAD insertion, myelomeningocele closure, and shunt insertion, all of which have a relatively lower reoperation rate.

In the multivariate analysis, patients who were admitted from the ED prior to their index operation were two times more likely to undergo an unplanned reoperation within 48 hours. Furthermore, index procedures starting after 3 PM and before 7 AM were twice as likely to require unplanned reoperation compared with others. Last, reoperations were more common after shunt surgery than after other surgical categories.

\section{Discussion}

\section{Reoperations in Neurosurgery}

The study of reoperations as a quality metric has been suggested in general surgery1,4 but has only recently received attention in the field of neurosurgery. The goal of such analysis is to identify modifiable factors to reduce reoperations and eventually improve patient outcome. We chose to focus on 48-hour reoperation rates to identify immediate perioperative factors that could be targeted for improvement. Although no studies have directly addressed this topic, there is some precedence to the analysis of very early reoperations. Mazur et al. ${ }^{7}$ analyzed early complica-
TABLE 5. Multivariate analysis of clinical and demographic factors associated with unplanned reoperations within 48 hours

\begin{tabular}{lcr}
\hline \multirow{2}{*}{ Independent Variable } & \multicolumn{2}{c}{$\begin{array}{c}\text { Unplanned Reops w/in } 48 \mathrm{Hrs} \\
(\mathrm{n}=159)\end{array}$} \\
\cline { 2 - 3 } & \multicolumn{1}{c}{ OR $(95 \% \mathrm{Cl})$} & $\mathrm{p}$ Value \\
\hline Age $<1 \mathrm{yr}$ & $0.92(0.59-1.44)$ & 0.714 \\
\hline After-hr surgery* & $2.01(1.43-2.83)$ & $<0.001$ \\
\hline Urgent surgery & $1.40(0.90-2.16)$ & 0.135 \\
\hline Admission from ED & $1.97(1.32-2.96)$ & 0.001 \\
\hline NICU admission after surgery & $0.44(0.16-1.20)$ & 0.107 \\
\hline Index surgery category & & \\
\hline Shunt & $5.74(2.73-12.06)$ & $<0.001$ \\
\hline Craniotomy & $2.02(0.92-4.45)$ & 0.082 \\
\hline Other & \multicolumn{2}{c}{ Reference } \\
\hline
\end{tabular}

Boldface type indicates statistical significance.

* After-hour surgery was defined as procedure start time after 3 PM and before 7 AM.

tions and reoperations during 127 occipitocervical fusions in pediatric patients. They reported 4 reoperations within the first 48 hours due to malpositioned cervical screws. This was an important factor as the later introduction of the O-arm led to no further instances of immediate hardware failure. Foroulis et al. ${ }^{3}$ analyzed early reoperations in patients who underwent general thoracic surgical procedures and reported that 33 of 719 patients underwent early reoperations. In this category, 9 patients were found to have required reoperations for postoperative bleeding, the majority of which occurred on the 1st postoperative day.

A comprehensive literature search on reoperations in neurosurgery revealed only 4 studies on the topic, $, 5,6,8,9$ with no studies specifically examining 48 -hour reoperation rates.

Mukerji et al. ${ }^{9}$ reviewed their records for pediatric patients treated over a 2-year period at a tertiary care center in England. A total of 410 operations were analyzed, and the unplanned, 30-day reoperation rate was $17 \%$. The two main risk factors associated with reoperations were a CSF diversion procedure and an urgent procedure, which was defined as one that was performed outside the hours of 8 AM to 5 PM. An important factor to note is that trainees performed $52 \%$ of all urgent operations, sometimes without the presence of an attending neurosurgeon. However, whether the surgeon was an attending surgeon or a trainee did not correlate with the likelihood of reoperations in their univariate analysis.

Marini et al. ${ }^{6}$ studied unplanned reoperation rates as a tool to identify surgical adverse events. Over a course of six months, 1,006 neurosurgical procedures for patients over 18 years of age in a university hospital in France were prospectively followed. The 30-day unplanned reoperation rate was $9.2 \%$. The causes of the reoperation were further dichotomized into those due to adverse events versus those resulting from the natural history of the disease. The rate of reoperation due to an adverse event was reported as 7.3\%. An overall classification of the adverse events into hemorrhagic, infectious, and other is provided, but details on the index surgeries were not reported. 
Lepänluoma et al. ${ }^{5}$ studied neurosurgical reoperations before and after implementation of the WHO surgical checklist over a 4-year period in Finland. In their study, only complication-related reoperations were reported, and planned reoperations and reoperations due to natural disease progression were not included. They found a decrease in their reoperation rate from $3.3 \%$ to $2.0 \%$ following the checklist implementation; however, the time interval during which these reoperations happened was not specified. Overall, the most common cause for reoperation was wound infection (45.6\% before and 38.9\% after checklist implementation). The two most common index operations that led to reoperations were shunt-related procedures and craniotomies for tumor resection.

McLaughlin et al. ${ }^{8}$ reviewed their adult and pediatric cases at a major US medical center over a 4-year period, identifying 6912 cases, and they found an unplanned return-to-operating-room rate of $2.6 \%$ during a 7 -day period. When the index surgery was a shunt-related procedure, the 7-day unplanned reoperation rate was 5.5\%. This is consistent with our 2-day unplanned shunt reoperation rate of $2.78 \%$ and suggests that an additional $2 \%-3 \%$ of patients may undergo reoperations between 2-7 days postoperatively. When the index surgery was a craniotomy for tumor resection or decompressive hemicraniectomy, the 7-day unplanned reoperation rates were $2.0 \%$ and $4.2 \%$, respectively. Again, this is consistent with our results of 2 -day reoperation rates of $0.9 \%$ and $1.7 \%$ for these 2 categories, respectively. Despite the differences in patient populations, health care delivery system and localities, the results are surprisingly similar and suggest that reoperation rates (in the defined, short time frame) may be considered as a useful benchmark.

\section{Areas for Improvement}

Analysis of our results revealed an overall reoperation rate of $2.78 \%$ and an unplanned reoperation rate of $2 \%$ in the 48-hour period after the conclusion of the index surgery. The multivariate analysis highlighted two key areas that could be targeted for improvement: admission from the ED and cases starting after 3 PM and before 7 AM. The finding of a higher reoperation rate for patients admitted from the ED may reflect the overall higher acuity of these patients' pathology, but it may also reflect socioeconomic factors that could promote more frequent ED usage in certain patient groups. Further study is needed to differentiate the underlying causes of this observed phenomenon so that intervention can be targeted. The finding of a higher reoperation rate being correlated with after hour surgery could be a reflection of suboptimal patient care. At our institution, a shift change for the operating room staff occurs at these hours, and after hour workers are not as familiar with neurosurgical cases. This could be a potential area for investigation. In their study, Mukerji et al. ${ }^{9}$ also found a higher reoperation rate for the index procedures performed outside the hours of 8 AM to 5 PM. One potential difference to account for their higher overall reoperation rate could be that all pediatric cases at our institution have an attending neurosurgeon scrubbed in, regardless of the hour. We are in the process of implementing some quality improvement reforms to specifically target these off-hour surgeries. These changes include a heightened awareness to protocol on the part of the attending neurosurgeon and resident covering these cases, better education for the involved staff, and restricted traffic flow into the operating room around shift change.

Within the subset of our unplanned reoperations, the majority $(73.5 \%)$ were shunt related. Recently, Venable et al. ${ }^{13}$ attempted to refine the analysis of shunt-related reoperations by focusing on the "Preventable Shunt Revision Rate." Preventable failure included infection, a malpositioned proximal or distal catheter, or an inadequately secured valve. This was not specifically measured in our study and is certainly an area for future investigation. When we examine our shunt reoperations specifically for preventability, several points are worth mentioning. One can argue that intraoperative imaging could be beneficial. However, given the overall small number of malpositioned catheters in our study, confirming a substantial benefit would likely require accumulating data over several years. Aside from heightened monitoring of operating room traffic, we believe we may be approaching the limits of what is possible with current technology in reducing infection. As an academic institution and a training program, we do not think it is practical to limit a single surgeon to the case. Finally, our study did not address the possibility that some of these reoperations and ED utilization may occur in a small group of patients whose shunt functions are difficult to assess and who habitually use the ED as point of access to care. If such a group of patient can be clearly identified, further targeted care may be possible.

\section{Conclusions}

Very early reoperation rates may allow us to study factors that could be definitively targeted to reduce reoperations and improve patient outcomes. We could only attribute a small number of our 48 -hour reoperations to modifiable intraoperative events. The usefulness of an early reoperation rate as a quality measure remains uncertain.

\section{References}

1. Birkmeyer JD, Hamby LS, Birkmeyer CM, Decker MV, Karon NM, Dow RW: Is unplanned return to the operating room a useful quality indicator in general surgery? Arch Surg 136:405-411, 2001

2. Buchanan CC, Hernandez EA, Anderson JM, Dye JA, Leung M, Buxey F, et al: Analysis of 30-day readmissions among neurosurgical patients: surgical complication avoidance as key to quality improvement. J Neurosurg 121:170-175, 2014

3. Foroulis CN, Kleontas A, Karatzopoulos A, Nana C, Tagarakis $\mathrm{G}$, Tossios P, et al: Early reoperation performed for the management of complications in patients undergoing general thoracic surgical procedures. J Thorac Dis 6 (Suppl 1):S21S31, 2014

4. Kroon HM, Breslau PJ, Lardenoye JW: Can the incidence of unplanned reoperations be used as an indicator of quality of care in surgery? Am J Med Qual 22:198-202, 2007

5. Lepänluoma M, Rahi M, Takala R, Löyttyniemi E, Ikonen TS: Analysis of neurosurgical reoperations: use of a surgical checklist and reduction of infection-related and preventable complication-related reoperations. J Neurosurg 123:145152,2015 
6. Marini H, Merle V, Derrey S, Lebaron C, Josset V, Langlois $\mathrm{O}$, et al: Surveillance of unplanned return to the operating theatre in neurosurgery combined with a mortality-morbidity conference: results of a pilot survey. BMJ Qual Saf 21:432438, 2012

7. Mazur MD, Sivakumar W, Riva-Cambrin J, Jones J, Brockmeyer DL: Avoiding early complications and reoperation during occipitocervical fusion in pediatric patients. J Neurosurg Pediatr 14:465-475, 2014

8. McLaughlin N, Jin P, Martin NA: Assessing early unplanned reoperations in neurosurgery: opportunities for quality improvement. J Neurosurg 123:198-205, 2015

9. Mukerji N, Jenkins A, Nicholson C, Mitchell P: Unplanned reoperation rates in pediatric neurosurgery: a single center experience and proposed use as a quality indicator. J Neurosurg Pediatr 9:665-669, 2012

10. Sarda S, Bookland M, Chu J, Shoja MM, Miller MP, Reisner SB, et al: Return to system within 30 days of discharge following pediatric non-shunt surgery. J Neurosurg Pediatr 14:654-661, 2014

11. Shah MN, Stoev IT, Sanford DE, Gao F, Santiago P, Jaques DP, et al: Are readmission rates on a neurosurgical service indicators of quality of care? J Neurosurg 119:1043-1049, 2013

12. Tejedor-Sojo J, Singleton LM, McCormick K, Wrubel D, Chern JJ: Preventability of pediatric 30-day readmissions following ventricular shunt surgery. J Neurosurg Pediatr 167:1327-1333, 1333.e1, 2015
13. Venable GT, Rossi NB, Morgan Jones G, Khan NR, Smalley ZS, Roberts ML, et al: The Preventable Shunt Revision Rate: a potential quality metric for pediatric shunt surgery. J Neurosurg Pediatr 18:7-15, 2016

14. Wrubel DM, Riemenschneider KJ, Braender C, Miller BA, Hirsh DA, Reisner A, et al: Return to system within 30 days of pediatric neurosurgery. J Neurosurg Pediatr 13:216-221, 2014

\section{Disclosures}

The authors report no conflict of interest concerning the materials or methods used in this study or the findings specified in this paper.

\section{Author Contributions}

Conception and design: Chern. Acquisition of data: Bozeman, Sarda. Analysis and interpretation of data: Chern, Roy, Bozeman, Sarda. Drafting the article: Chern, Roy, Chu, Bozeman, Sawvel. Critically revising the article: Chern, Roy, Chu, Sawvel. Reviewed submitted version of manuscript: all authors. Statistical analysis: Bozeman, Sarda.

\section{Correspondence}

Joshua J. Chern, 5455 Meridian Mark Rd. NE, Ste. 540, Atlanta, GA 30342. email: joshua.chern@choa.org. 